\title{
VASCULAR REFLEXES IN SPINAL SHOCK
}

\author{
By J. R. Silver, M.B., B.S., M.R.C.P.Ed. \\ Liverpool Regional Paraplegic Centre
}

A PATIENT who has sustained a complete transection of the cervical cord above the sympathetic outflow loses those vascular reflexes that depend upon intact efferent pathways from the medullary centres such as forearm vasoconstriction in response to the Valsalva manoeuvre and reflex skin vasodilatation in response to indirect heating. There are other vascular reflexes that are still preserved, vasoconstriction of the digital blood vessels in response to a deep breath, vasodilatation of the forearm blood vessels in response to elevation of the lower limbs and vasoconstriction of the forearm blood vessels in response to distension of the bladder. These latter reflexes presumably being mediated at a spinal level. During the stage of spinal shock the anal reflex is usually preserved. The length of time that plantar flexor withdrawal and the tendon reflexes are abolished is variable. For this reason the present series of observations were made to determine how soon after an acute spinal transection spinal vascular reflexes could be detected, and what contribution the capacity venous system makes to the maintenance of the circulation in spinal man.

\section{SUBJECTS}

Fifteen patients were studied, the level of the cord lesion varied between $\mathrm{C}_{3}$ and $\mathrm{T}_{4}$. In $\mathrm{I}_{4}$ of the $\mathrm{I} 5$ patients complete loss of sensory and motor function as well as loss of control of bladder and bowel function indicated that there was a complete loss of functional continuity of the cord at the appropriate level. Eleven of the I5 patients had a complete lesion above the sympathetic outflow at TI. Three of the remaining four patients had only sparing of light touch in the upper three thoracic segments, one patient had a complete lesion at $\mathrm{T}_{4}$. Thirteen patients were male, two were female, their ages ranged between I 4 and 54 years. They were all paralysed as a result of fracture on fracture dislocations of their cervical vertebra. They can readily be divided into two groups. The early group nine patients were studied between I and 26 days after injury when the tendon reflexes were either absent or depressed, although the anal reflex was preserved, and there was some sign of flexion withdrawal on plantar stimulation, and the late group six patients in whom the tendon reflexes in the paralysed area were exaggerated and reflex activity had returned to the bowel and bladder. These patients were studied between 6 and I I months after injury.

\section{METHODS}

Hand and forearm blood flows were measured by means of water-filled venous occlusion plethysmographs. The water in these were kept between $30^{\circ}-32^{\circ} \mathrm{C}$. and $34^{\circ}-36^{\circ}$ respectively. The technique of Barcroft and Swan (1953) was followed closely. 
The heart rate was recorded in some of the experiments on an Ediswan Electroencephalograph machine. The blood pressure was recorded intermittently on a ward sphygmomanometer.

The patient was brought to the Examination Room on his bed with his head supported by pillows. Hand and forearm blood flows, the heart rate and blood pressure were recorded for a control period of 30 to 40 minutes. The procedure differed in the early and the late group of patients.

The early group who were still on traction due to their recent injury were studied on only one or two occasions. In some patients the blood flow in their hands in response to a deep breath was recorded. In others the blood pressure changes in response to distension of the bladder was studied.

The late group who were up in wheelchairs were studied on three to five occasions, in these the Valsalva manoeuvre was performed by the subject blowing against a mercury column, through a large bore mouth piece and holding it at $40 \mathrm{~mm}$. $\mathrm{Hg}$ for Io seconds.

Indirect heating was achieved by heating the subject's trunk and lower limbs by a heat cradle, which was screened from the patient by a wooden board, covered with silver foil. Oral temperatures were taken at intervals during the indirect heating, with a clinical thermometer for a minimum of 3 minutes, and the skin temperature of the forehead, chest, shoulders and elbows were measured with a 'Biatherm Baby' thermistor.

The posture of the subject was altered by placing him upon a tilting table and tilting the table at $15^{\circ}, 30^{\circ}$ and $45^{\circ}$ head up for short periods of 30 to 350 seconds, the experiment was terminated if the patient felt faint. On a limited number of occasions prior to tilting, the subject's legs were first elevated for a few minutes to drain as much blood out of them as possible, and then specially large cuffs were inflated around the thighs to above arterial pressure to trap as much blood as possible in the capacity vessels of the trunk. The tilting experiments were then repeated with the cuffs inflated. Cystometry was carried out by the technique of Yeates (1954), as described by Silver (1969).

The occurrence of spasms, micturition, sweating, or complaints of headache or breathlessness by the patient were carefully noted, since it is known that these symptoms can be associated with marked changes in the hand and forearm blood flows in spinal man.

\section{RESULTS}

The results of the Valsalva manoeuvre and indirect heating in seven patients with complete cervical lesions has already been described in a previous paper Silver (1965). The Valsalva was blocked and there was no reflex vasodilatation, indicating that not only had the motor and sensory tracts of the cord been interrupted, but also the spinal cord pathways subserving the transmission of sympathetic impulses. This confirmed that the reflex responses to the Valsalva manoeuvre, and indirect heating are mediated through the medullary centres. There is no reason to suppose that in the patients studied within hours of injury in whom such tests could not be carried out would have behaved any differently.

Early stages-Inspiratory Vasconstriction. In I948 Gilliatt reported inspiratory vasoconstriction responses in the hands in normal subjects. He also showed, in co-operation with Guttmann and Whitteridge (1948), that this was 


\section{TABLE I}

Blood Flow in the Hands in response to Deep Inspiration in Three Subjects with Complete Spinal Cord Transections above the Sympathetic Outflow, soon after Injury

(Hand blood flow in $\mathrm{m} . / 100 \mathrm{ml}$. tissue)

(Blood flow ml./100 ml./per min.)

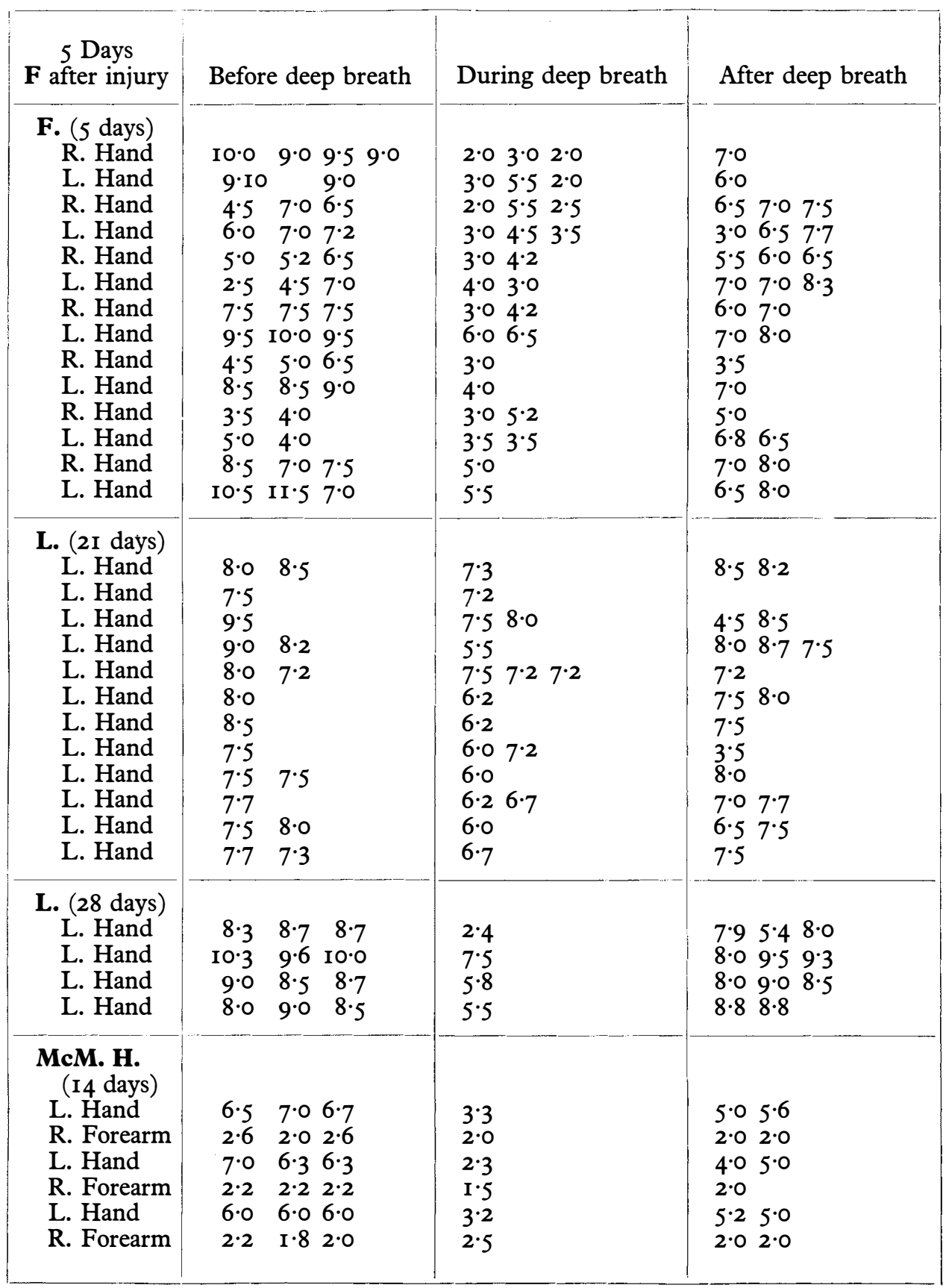


also present in patients with a functional break in the continuity of the cord above the sympathetic outflow. From this they concluded that this was a spinal reflex mediated through the thoracic cord. These patients were studied some years after injury and there have been no investigations to determine if this reflex is present or abolished in the stage of spinal shock and if abolished when it reappeared. This was studied in three patients (see table I).

Case F. While still in the stage of spinal shock some five days after sustaining a physiological interruption of her cord below $\mathrm{C}_{7}$ the tendon reflexes were absent, plantar stimulation produced some flexor withdrawal of the lower limbs. The vital capacity was 0.9 litres. Her blood pressure was I I0/70, pulse between 72 and 84 . Blood flows were measured in both hands simultaneously, there was considerable fluctuation which varied between 3.5 and II $.5 \mathrm{ml} . / 100 \mathrm{ml}$. per min. She took seven deep breaths and in each case the blood flow in both hands dropped markedly and consistently while the breath was held to return to the mean resting level after expiration. The greatest reduction being to 20 per cent the resting flow, the fall being from $10 \mathrm{ml}$. per min to 2 ml. min. (fig. I).

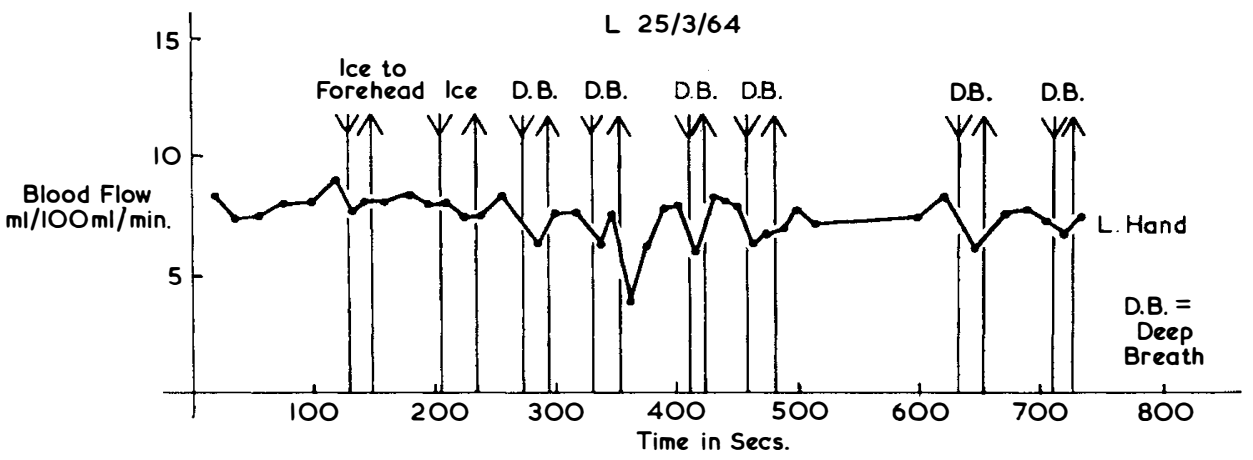

FIG. I

Case F. Five days after sustaining a complete cord lesion at $\mathrm{C}_{7}$, blood flows were recorded simultaneously from both hands. A deep breath consistently elicited a simultaneous drop in the blood flows of the hands, which returned to normal upon expiration.

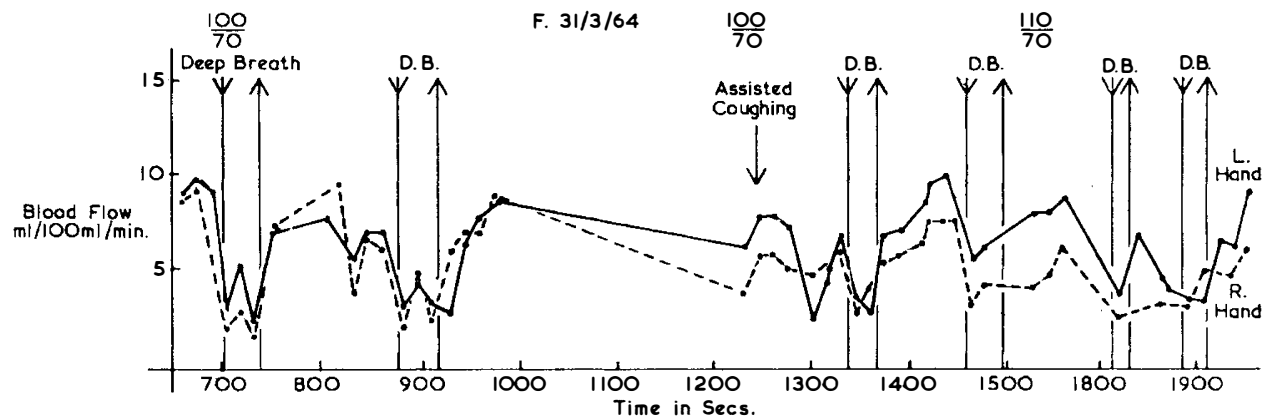

FIG. 2

Case L. Twenty-one days after sustaining a complete cord lesion at C5. A maximum breath of $400 \mathrm{ml}$. consistently produced a small drop in the blood flow of the left hand, which returned to normal upon expiration. 
Case L. was studied on two occasions, the first time 3 weeks after injury. At that stage she had a complete loss of power and sensation below $\mathrm{C}_{5}$, her vital capacity was only $400 \mathrm{ml}$., blood flow was measured in her left hand only. She took 12 deep breaths, on all occasions there was a drop in the blood flow, but this was not as marked as in the other patients being of the order of 80 per cent. After expiration the flow returned to normal. Application of ice to her forehead in the nonparalysed area produced no change

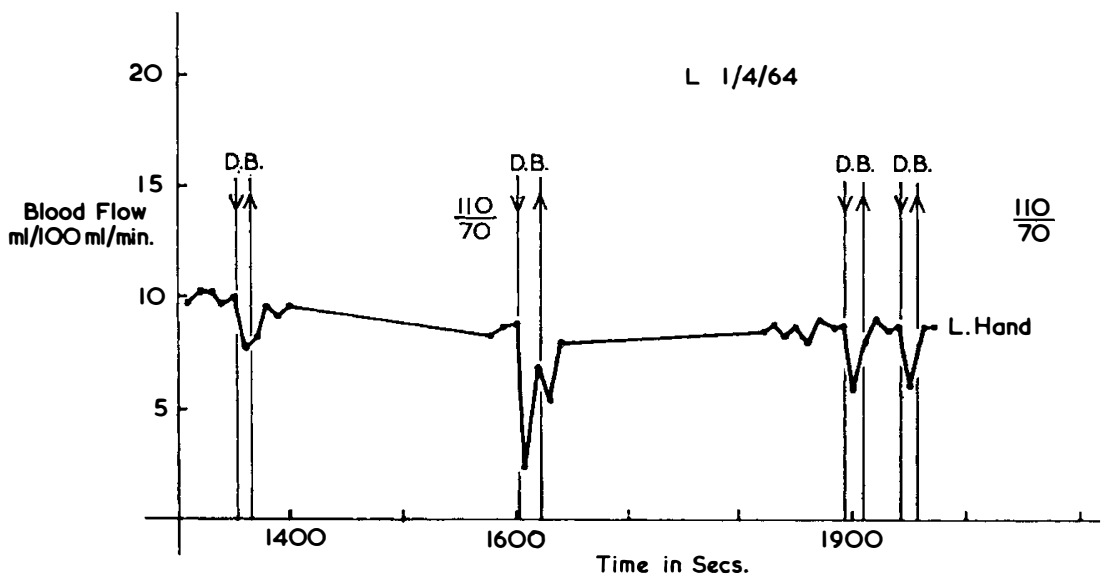

FIG. 3

Cass L. Twenty-eight days after sustaining a complete cord lesion at $\mathrm{C}_{5}$, a maximum breath of I IOO ml. produced a much greater drop in blood flow than a week previously.

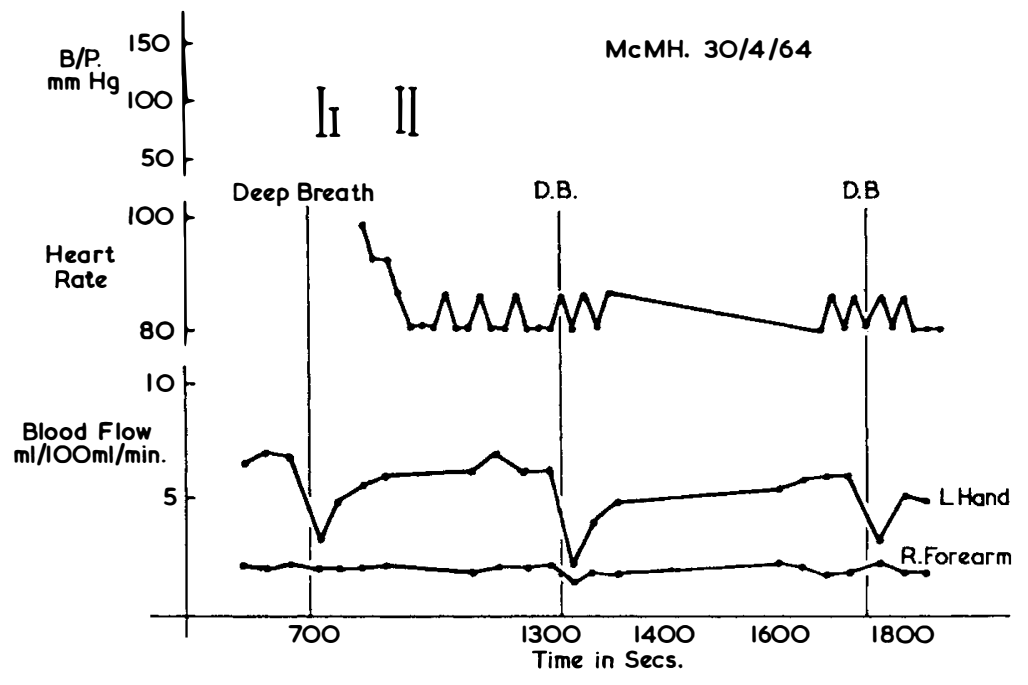

FIG. 4

Case McM. H. Fourteen days after sustaining a complete cord lesion below C8, a deep breath produced a fall in the left-hand blood flow, but no consistent change in the forearm flow indicating that the reflex was confined to the blood vessels of the hand (which are predominantly in the skin). 
in blood flow-indicating that there was complete interruption of the cord from the medullary centres (fig. 2).

A week later the experiment was repeated. She was still complete, but at this stage she was spastic in her lower limbs with increased tendon reflexes and extensor plantar responses. Her vital capacity had risen to I I litres a nearly threefold increase. She took four breaths and the fall in blood flow was much more marked, being of the order of 30 to 50 per cent. (fig. 3).

Case J. McM. H. was studied I4 days after sustaining a complete transection below C8 with total loss of power and sensation. Blood flow was measured in the right forearm and left hand. In his case there was a striking fall in the hand blood flow when three deep breaths were taken, whereas the forearm blood flow remained steady, indicating that this reflex was confined to the skin blood vessels (fig. 4).

Autonomic Hyperreflexia. In 1947 Guttmann and Whitteridge and in I953 Cunningham et al. studied the autonomic response to distension of the bladder in tetraplegic patients. They showed this caused hypertension, bradycardia and if continued long enough severe headaches and difficulty in breathing. In I963 Silver showed that this was accompanied by a fall in the forearm blood flow.

All these patients were studied at a considerable interval after the spinal injury. There have been no studies in the stage of spinal shock to determine when this reflex appears.

J. M. had sustained a complete transverse spinal cord lesion below C6 on 2.5.70 as the result of a motor cycle accident. 7 days after injury his tendon reflexes were absent, but his anal reflex was present. He was being treated with intermittent catheterisation. At 6 a.m. on 9.5.70 his bladder was drained, however at Io a.m. he complained of severe breathlessness, he was most distressed but not cyanosed. His apex beat was extremely forceful, but he made no complaint of headache. His respiration rate was 36 breaths per minute, he had scattered rhonchi, his blood pressure was 200/90, heart rate 85, and chest X-ray was normal. His blood pressure rose to $210 / 100$, his bladder was palpable and pulse 90. A catheter was passed $\mathrm{I}, 600 \mathrm{ml}$ was drained. There was a dramatic change in his breathlessness, the respiration rate dropped almost immediately to 30 and the blood pressure to $180 / 70$, the heart rate dropped to 70 . Over the next two hours his condition improved, the systolic pressure being the last to fall. In his case there was no bradycardia or headache accompanying the hypertension and the chest symptoms predominated.

These changes in the pulse, blood pressure and respiration were part of the reflex response of autonomic hyperreflexia. Six days later the experiment was repeated under controlled conditions and a cystometrogram was performed this only produced a small rise in blood pressure and no change in respiration with $350 \mathrm{ml}$. of fluid in the bladder.

Cystometry was carried out in three further patients (table 2). The initial examination on J. E., a patient with a complete lesion at $\mathrm{C}_{4}$, at one day produced no changes in the blood pressure, but subsequent examination at 24 and 40 days produced a definite increase of $20 \mathrm{~mm}$. of $\mathrm{Hg}$ in the diastolic and systolic readings. A similar increase in the blood pressure was found in D. Ma, a patient with an incomplete cervical cord injury at 26 days, whereas D. Mo, a patient with a complete lesion at $\mathrm{D}_{4}$, studied at $\mathrm{I} 4$ days showed no changes. He was similar to the initial examination J. E. although at this stage tendon reflexes had returned to his lower limbs. 


\section{TABLE III}

Blood Pressure Responses to Cystometry in Four Subjects soon after Injury

(In all the patients the anal reflex was present)

\begin{tabular}{|c|c|c|c|c|c|c|c|c|c|c|c|}
\hline \multirow[b]{2}{*}{ Name } & \multirow{2}{*}{$\begin{array}{l}\text { Time after } \\
\text { injury }\end{array}$} & \multirow[b]{2}{*}{ Lesion } & \multicolumn{9}{|c|}{ ml. in bladder } \\
\hline & & & Nil & 50 & 100 & 150 & 200 & 250 & 300 & 350 & 1600 \\
\hline J. E. & $\begin{array}{l}\text { I day } \\
24 \text { days } \\
40 \text { days }\end{array}$ & $\begin{array}{c}\text { Complete } \\
\text { C4 }\end{array}$ & $\begin{array}{l}90 / 70 \\
100 / 60 \\
116 / 70\end{array}$ & $\begin{array}{c}90 / 70 \\
- \\
110 / 70\end{array}$ & $\begin{array}{r}90 / 70 \\
98 / 66 \\
\text { I 10/70 }\end{array}$ & $\begin{array}{c}90 / 70 \\
- \\
120 / 75\end{array}$ & $\begin{array}{r}90 / 70 \\
\text { I } 4 / 80 \\
\text { I30/75 }\end{array}$ & $\begin{array}{l}90 / 70 \\
I 20 / 80 \\
134 / 80\end{array}$ & $\begin{array}{c}90 / 70 \\
- \\
-\end{array}$ & $\begin{array}{c}90 / 70 \\
- \\
-\end{array}$ & $\begin{array}{l}- \\
-\end{array}$ \\
\hline D. $\mathrm{Ma}$ & 26 days & $\begin{array}{c}\text { Incomplete } \\
\text { C6 }\end{array}$ & $100 / 50$ & $100 / 60$ & IIo/60 & $120 / 60$ & $120 / 80$ & $120 / 80$ & - & - & - \\
\hline D. Mo & I5 days & $\begin{array}{c}\text { Complete } \\
\mathrm{D}_{4}\end{array}$ & $100 / 70$ & - & I IO/76 & - & $110 / 76$ & I IO/74 & - & IIO/70 & - \\
\hline \multirow[t]{2}{*}{ J. M. } & 7 days & $\begin{array}{c}\text { Complete } \\
\mathrm{C}_{7}\end{array}$ & $100 / 50$ & \multicolumn{7}{|c|}{ Filled by the patient secreting urine } & $210 / 100$ \\
\hline & I3 days & & $100 / 50$ & IIO/55 & $120 / 60$ & - & $120 / 60$ & - & $120 / 60$ & $120 / 60$ & - \\
\hline
\end{tabular}




\section{TILTING EXPERIMENTS}

Duration of the Tilt in Relation to the Incidence of Feeling Faint. The object of these experiments was not to make the patient faint but to investigate the cardio-vascular responses to progressive venous pooling, consequently the experiments were terminated as soon as the patient was distressed. Only one patient was tilted on one occasion at an angle of $15^{\circ}$. He did not feel faint. In six patients, 12 tilts were made to $30^{\circ}$ for a maximum duration of $350 \mathrm{sec}$. and only one patient felt faint at $\mathrm{I} 8 \mathrm{O} \mathrm{sec}$. Whereas of the four paitents tilted on six occasions to $45^{\circ}$, two patients felt faint at 100 to 210 sec.

\section{HEART RATE DURING TILTING}

$15^{\circ}$ Tilt. There was only a minimal increase in heart rate during this procedure. The heart rate rising from a resting rate of 66 to 72 during the tilt.

$3^{\circ}$ Tilt. There was a marked tachycardia. The heart rate rising from a resting rate of between 54 and 72, average 6I, to 78 to II 4 with an average of 93 . When the patient was placed in the horizontal position, there was a bradycardia (fig. 5) 48 to 72 with an average of 58 below the pretilt rate, the heart eventually returning to the resting rate.

$45^{\circ}$ Tilt. Only four patients were tilted on the table to this position. Similar but more marked changes were seen to the results of a $30^{\circ}$ tilt. The resting rate in the horizontal position ranged between 54 and 84 beats per min. with an average of 66 . The tachycardia on being tilted was much more marked rising to between 90 and 126 beats per min. with an average of I04. On reassuming the horizontal position the bradycardia was more marked than in the $30^{\circ}$ tilt, the range being 42 to 60 with an average of $56^{\circ}$.

Blood Pressure $15^{\circ}$. Only one patient $M$ was tilted to $15^{\circ}$ on one occasion. He was not distressed at all by this and his blood pressure dropped during the procedure from a level to $170 / 120$ to $170 / 100$ to $130 / 90$.

Blood Pressure $30^{\circ}$. Five patients were tilted twice and one patient, $\mathrm{P}$, was tilted three times to this position. In one patient no B.P. records were taken during this procedure and in two others P. and T. these were recorded on only one occasion, but all patients where this was available there was a profound fall in blood pressure. In one patient, O. D., the blood pressure dropped from raising levels of $130 / 90$ to $100 / 90$ to become unrecordable in 200 seconds. In $M$. it dropped from resting levels of $\mathrm{I} I \mathrm{O} / 80$ to systolic of $60 / 0$. The fall in P. case was less dramatic, but there was a consistent drop in both systolic and diastolic pressure of $20 \mathrm{~mm}$. Hg. In the majority of patients the restoration of the horizontal position restored the blood pressure to slightly higher levels than the resting pretilt levels, but this hypertension was only of the order of $10 \mathrm{~mm}$. mercury and was not sustained.

Blood Pressure $45^{\circ}$. Four patients were tilted to $45^{\circ}$ in three patients the blood pressure very rapidly fell. The same transient hypertension was observed on restoring the patient to the horizontal position as was seen in the $30^{\circ}$ tilt. 


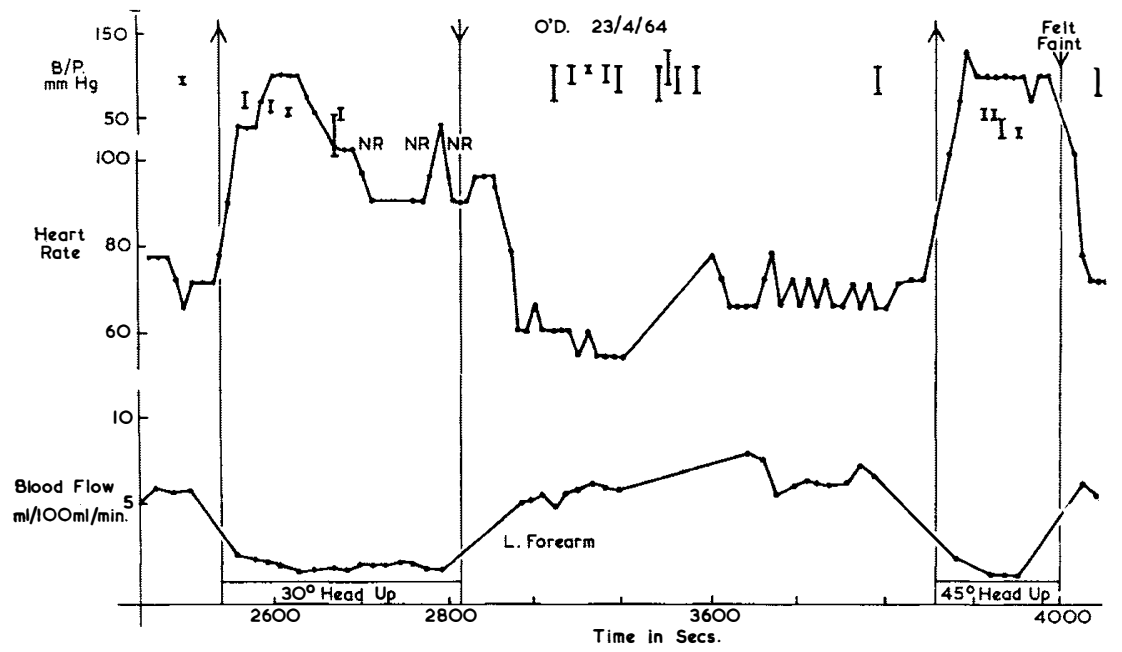

FIG. 5

Case O'D., who had sustained a complete cord lesion below $\mathrm{C}_{7}$ some eight months previously. The response to tilting $45^{\circ}$ head up is qualitatively the same as $30^{\circ}$. There is a fall in blood pressure in forearm blood flow, the tachycardia is more pronounced and sustained, and the patient can only tolerate the $45^{\circ}$ tilt for a shorter period before he feels faint. Note the transient bradycardia following the restoration to the horizontal after the $30^{\circ}$ tilt.

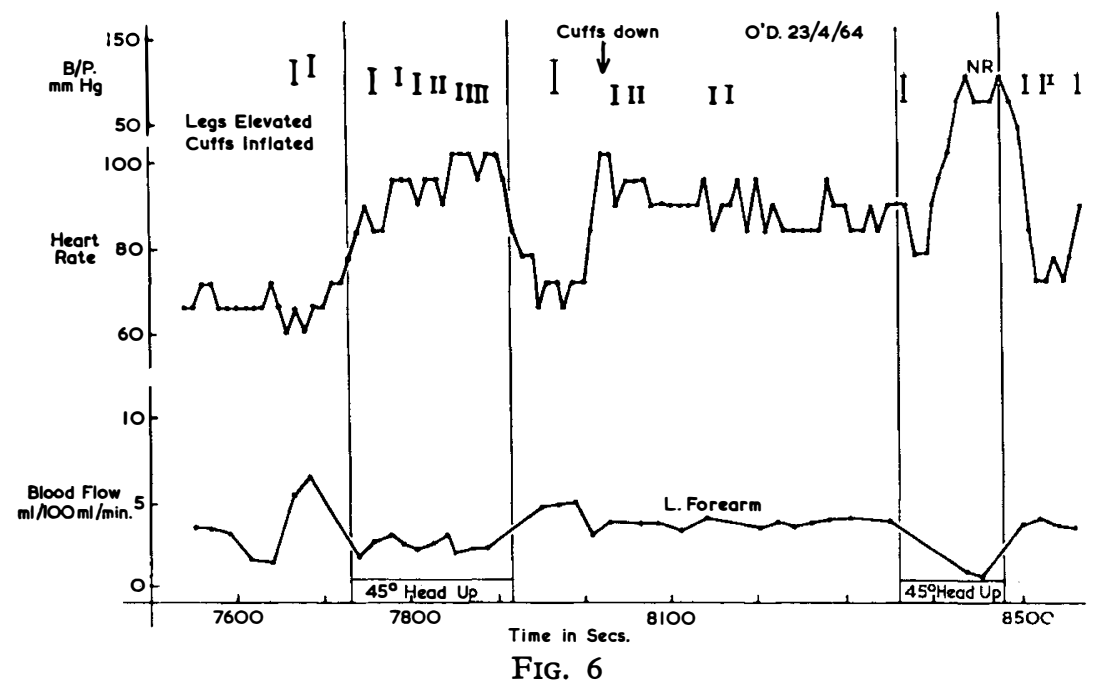

Case O'D., who had sustained a complete cord lesion below C7. Note the forearm vasodilatation and the bradycardia in response to elevation of the lower limb. When he was tilted to $45^{\circ}$, there was a tachycardia and a fall in the blood pressure and forearm blood flow, but this was not nearly so much as when the tilt was repeated with the cuffs off, the blood pressure becoming unrecordable (see also fig. 5). 
Tilting with Arterial Cuffs of the Lower Limbs. The elevation of the lower limbs and the application of cuffs frequently elicited spasms and made it impossible to subsequently tilt the patient with the result that only a limited number of experiments were carried out in this way. One patient, O'D., was tilted to $30^{\circ}$ and $45^{\circ}$ and one patient, J. T., was tilted twice to $45^{\circ}$.

The elevation of the lower limbs to drain the blood out of them prior to the tilting procedure resulted in bradycardia, and an increase in the blood pressure, diastolic pressure in all cases being at least $\mathrm{IO} \mathrm{mm}$. $\mathrm{Hg}$ above the resting figures. The changes in the forearm blood flow were less constant.

On elevating the patient to $30^{\circ}$ and $45^{\circ}$ there was a fall in the blood pressure but this was only of the order of $20 \mathrm{~mm}$. $\mathrm{Hg}$ and the lowest diastolic pressure recorded was $70 \mathrm{~mm} \mathrm{Hg}$ compared with the profound drop when there were no cuffs and the blood pressure rapidly became unrecordable (fig. 6). A tachycardia also occurred, but this was not so fast as when there were no cuffs. The forearm blood flow dropped though not to the same degree as the blood pressure. The patients did not feel faint during any of the tilting procedures and they could tolerate the position of $45^{\circ}$ tilt, I 80 sec. without distress.

\section{DISCUSSION}

It is appreciated that in experiments of this nature it is desirable to have a continuous record of the central venous pressure, the arterial blood pressure and the cardiac output, but this would required arterial and venous catheterisation. The limitations of studies on the circulation based upon records of the peripheral blood flow, heart rate and blood pressure are apparent, however in the past much valuable information has been derived by these techniques (Shepherd, 1963). In the case of recently injured patients these may be the only observations available.

The finding that inspiratory vasoconstriction was present in three patients with complete lesions of their cervical cords within 3 weeks of injury, and that autonomic hyperreflexia could be detected in response to bladder filling as soon as 7 days after injury, indicate that these reflexes return at a very early stage. This is compatible with the finding that the anal and bulbo-caverosus reflexes are nearly always preserved in high cervical cord injuries, while the tendon reflexes are abolished, indicating that not all reflex function is depressed to the same extent.

Serial observations on the presence of inspiratory vasoconstriction were only carried out on one patient. These showed that the response was much more marked on the second occasion. However, it could not be determined whether the reflex was depressed initially, since stimuli of the same size could not be administered. The patient only being able to take a breath of $400 \mathrm{ml}$. on the first occasion, whereas on the second occasion the patient could take a breath of $\mathrm{I} I 00 \mathrm{ml}$.

A similar problem was posed by the observation that there was no change in the blood pressure when a cystometrogram was performed on the first day after injury, but on repeating the cystometrogram at 24 days in the same patient, quite definite changes in the blood pressure could be detected. Larger stimuli may be necessary in the acute stage of spinal shock to initiate the reflex. The filling of the bladder by $1600 \mathrm{ml}$. in a patient within 7 days of injury proved a more than adequate stimulus, whereas at a later stage the reflex may be elicited by a smaller stimulus. Alternatively it is known that the bladder when infected becomes more irritable and that greater pressures are generated within the bladder by smaller 
quantities of urine (Sommers \& Roberts, I967), and that the passage of time alters the excitability of the bladder wall rather than there being any alterations at a spinal level.

The feeling of faintness during tilting was related to two factors, the angle of tilt and its duration. It was abolished by prior elevation of the lower limbs and the application of cuffs, this suggested that the mechanism of the faint was pooling of blood in the lower limbs since when blood was trapped in the abdomen by cuffs it produced an increase in the blood pressure and upon tilting the feeling of faintness was not elicited. The tilting being endured for much longer periods.

In all patients the response to increasing the venous return by elevating the lower limbs was bradycardia, an increase in the blood pressure and forearm vasodilatation. This is in accordance with previous observations (Silver, 1965). The response to diminishing the venous return by tilting the patient was a compensatory tachycardia, a fall in the blood pressure and the forearm blood flow. The restoration of the patient to the horizontal position increased the venous return by releasing the blood pooled in the lower limbs. This increase in the venous return caused the bradycardia and a slight increase in the blood pressure, similar to the effect of elevating the lower limbs. This is in accordance with findings of Guttmann et al. (1963) following tilting. This would appear to indicate that the response to the heart to changes in the venous return is not mediated by the brain stem. It is interesting to note that Jennet (1970) has shown that the tachycardia in response to anoxia is similarly preserved in patients with spinal transection.

It is thus apparent that there are spinal reflexes that are present which maintain the circulation soon after injury, this is in accordance with the clinical observation since immediately after a cervical injury, the patients are not surgically shocked unless they have lost sufficient circulating blood volume due to their injuries to account for this.

There are many problems still to be answered to determine how soon these reflexes reappear. Are they in fact totally abolished immediately after injury, or are they depressed, or does their heightening subsequently indicate the increased excitability of the nervous system due to release from higher centres or is it due to irritation of the end organs due to infection?

\section{CONCLUSIONS}

I. During the stage of spinal shock when the tendon reflexes are abolished, the autonomic reflexes of inspiratory vasoconstriction, and autonomic hyperreflexia are preserved.

2. Fainting as a result of tilting a tetraplegic patient can be partially accounted for by trapping of blood in the venous system of the lower limbs.

3. There are considerable compensatory mechanisms present at a spinal level after a cervical cord transection to maintain the circulation, and they are operative soon after injury.

\section{SUMMARY}

Studies were made on I 5 patients with injuries in the cervical region. Blood pressure, forearm and hand blood flows and heart rate in response to a deep breath, bladder distension and tilting with and without arterial cuffs were carried out. Some studies were made during the period of spinal shock, these showed 
that inspiratory vasoconstriction and autonomic hyperreflexia in response to filling the bladder were present. Other studies were made on patients when the spinal shock had passed. These showed that the response to tilting was a fall in the blood pressure and forearm blood flow, this was accompanied by a tachycardia. This response was modified by the application of arterial cuffs to the lower limbs.

These findings were discussed and indicated that reflex autonomic control of the blood vessels could be mediated by the spinal cord isolated from the medullary centres in the stage of spinal shock.

\section{RÉSUMÉ}

Des recherches ont porté sur 15 malades avec des atteintes médullaires cervicales. Ont été étudiés: la tension artérielle, le débit sanguin au niveau de l'avant bras et de la main, le rythme cardiaque en réponse à une inspiration profonde, à une dilatation de la vessie et verticalisations avec ou sans brassard artériel. Certaines de ces études ont été faites au cours du choc spinal qui ont montré une vaso-constriction inspiratoire et une hyper réflectivité autonome en réponse au remplissage de la vessie. D'autres études ont été faites chez les malades une fois le choc spinal passé. Celles-ci ont montré que les réponses à la verticalisation résultaient en une chute de la pression artérielle et du volume circulatoire au niveau de l'avant bras, accompagnés d'une tachycardie. Ces réponses ont été modifiées par l'application d'un garrot artériel au nieveau des membres inférieurs. Les résultats sont discutés et indiqueraient que le réflexe autonome de contrôle vasculaire pourrait se faire au niveau de la moëlle épinière isolée des centres médullaires au cours du choc spinal.

\section{ZUSAMMENFASSUNG}

Studien an Blutdruck, Unterarm- und Hand- Blutströmung und Herzfrequenz ausgelöst durch tiefe Einatmung, Distension der Blase, Kippen mit und ohne arteriellen Manschetten wurden an I5 Patienten mit Verletzungen des Zervikalmarks ausgeführt. Einige Untersnohungen wurden während der Phase des spinalen Schocks uternommen. Sie zeigten, dass inspiratorische Vasokonstriktion und autonome Hyperreflexie durch Blasenfüllung ausgelöst werden konnte. Andere Untersuchungen wurden nach Beendigung des spinalen Schocks unternommen. Sie ergaben einen Fall des Blutdruck und des Blutstromes im Unterarm, begleitet bei Tachykardie. Diese Reaktion wurde modifiziert durch Anlegen von arteriellen Manschetten an die unteren Extremitäten.

Die Befunde wurden diskutiert und sie zeigen, dass eine autonome Reflexkontrolle der Blutgefässe durch den isolierten Rückenmarksabschnitt vermittelt wird.

Acknowledgments. I would like to thank the Action for the Crippled Child for the grant which paid my salary during which the majority of this work was carried out.

\section{REFERENCES}

Barcroft, H. \& Swann, H. J. C. (1953). Sympathetic Control of Human Blood Vessels. London: Arnold.

Cunningham, D. J. C., Guttmann, L., Whitteridge, D. \& Wyndham, C. H. (1953). f. Physiol. 121, 581.

Gilliatt, R. W. (I948). F. Physiol. 107, 76.

Gilliatt, R. W., Guttmann, L. \& Whitteridge, D. (1948). F. Physiol. 107, 67.

GutTMANN, L. WhitTeridge, D. (1947). Brain, 70, 36r.

Guttmann, L., \& Munro, A. F., Robinson, R. \& Walsh, J. J. (I963). Paraplegia, I, 4. JennetT, S. (1970). Paraplegia, 8, r.

SHEPHERD, J. T. (1963). Physiology of the Circulation in Human Limbs in Health and Disease. Philadelphia and London: Saunders.

Silver, J. R. (1965). Paraplegia, 2, 235.

Silver, J. R. (1969). Renal Failure in Paraplegia, by Silver, J. R. \& Tribe, C. R. London: Pitman.

SOMMERS, L. \& ROBERTS, J. A. (1966). F. Urol. 95, 502.

YEATES, K. (1954). Brit. F. Urol. 26, I66. 